\title{
A VIOLÊNCIA NA ÓTICA DE ALUNOS ADOLESCENTES DO DISTRITO FEDERAL
}

\author{
CANDIDO ALBERTO GOMES \\ Programa de Pós-Graduação em Educação da Universidade Católica \\ de Brasília e Unesco \\ clgomes@terra.com.br \\ CLAUDIA VALENZUELA \\ CLÁUDIO NEI NASCIMENTO DA SILVA \\ ENÉAS DE ASSIS PORTUGAL \\ HELLEN CRISTINA CAVALCANTE AMORIM \\ JANAÍNA PAIM \\ MARIA ÂNGELA DOS REIS SILVA TANNO \\ PATRÍCIA CRISTINA CHAVES RODRIGUES MORGADO
}

Mestres e Mestrandos em Educação pela Universidade Católica de Brasília

\section{RESUMO}

Esta pesquisa exploratória teve como objetivo captar as percepções de adolescentes matriculados em estabelecimentos educacionais do Distrito Federal sobre as violências nas escolas e nas comunidades. Considerando que a literatura constata que as violências são comuns às escolas públicas e particulares, embora com diferentes ocorrências, o trabalho focalizou em particular as diferenças entre alunos dos dois tipos de escolas. Para tanto foi utilizada a técnica de grupos focais. Os resultados indicam que, embora se confirme a presença de violências nas escolas públicas e particulares, cada uma é tratada de modo diferente, as primeiras apoiando-se, em parte, no trabalho da polícia, e as últimas mantendo controle preventivo de pessoas e seus movimentos. As conclusões remetem às teorias sociológicas conflituais da Sociologia da Educação e ao seu maior poder explicativo. Enfatizam a necessidade de a escola considerar as sociedades dos adolescentes e o seu protagonismo e dinamismo próprios, abrindo os olhos para as mudanças dentro de si e ao seu redor.

ADOLESCENTES - VIOLENNCIA - GRUPO FOCAL - SOCIOLOGIA DA EDUCAÇÃO

Agradecemos à Professora Miriam Abramovay, do Programa de Graduação em Educação da Universidade Católica de Brasília, as inestimáveis e dedicadas orientações, a preparação para o trabaIho de campo e o constante estímulo intelectual. As opiniões e análises, entretanto, representam exclusivamente a posição dos autores. 
ABSTRACT

HOW ADOLESCENT STUDENTS PERCEIVE VIOLENCES AT SCHOOLS AND IN THE COMMUNITIES? This exploratory research project aims to analyse the perceptions of adolescents enrolled in public and private schools of the Federal District on violences in their schools and commnities. As the literature presents evidence that violences are common to both types of institutions, in spite of diverse characteristics, this study focused particularly upon similarities and differences between their students. The study gathered data using focus groups. Results confirm the occurrence of violences, however, both types of schools use different strategies to deal with them. Public schools often expect police support, whereas private ones maintain preventive control of persons and their movements. Conclusions emphasize the greater explanatory power of conflict theories in Sociology of Education, as well as the need of the schools to be aware of changes inside and around them, considering the adolescent societies and their own dynamism and active roles.

ADOLESCENTS - VIOLENCE - FOCUS GROUPS - SOCIOLOGY OF EDUCATION

Brasil não é um país singular no que se refere às violências em geral e às violências nas escolas. Em face de tais problemas, que parecem acentuar-se cada vez mais, têm sido realizadas pesquisas com diferentes graus de abrangência. Neste conjunto de esforços, a Unesco se destaca não só pela realização de investigações, como pela publicação e tradução de literatura. Aprofundando a atuação em favor de uma cultura de paz, a Universidade Católica de Brasília e a Unesco se uniram para constituir, em 2002, o Observatório de Violências nas Escolas-Brasil, unidade de ensino, pesquisa e extensão. Este trabalho constitui um dos frutos de tal projeto na área da investigação. Embora exista pelo menos um alentado estudo sobre a juventude no Distrito Federal (Waiselfisz et al., 1998), esta pesquisa, de caráter exploratório, analisou as percepções sobre as violências - dentro e fora dos estabelecimentos de ensino -, de adolescentes matriculados em escolas públicas e particulares, inclusive confessionais, do Plano Piloto de Brasília e de cidades satélites. Esta aproximação, e ao mesmo tempo este recorte da realidade, chamam a atenção para a seriedade dos problemas e sugerem algumas alternativas.

\section{O QUE DIZEM AS PESQUISAS?}

As violências nas escolas constituem desafios a inúmeros países, em especial do ocidente. Entretanto, cumpre não exagerar os fatos por meio de um 
discurso alarmista, com freqüência de conteúdo e interesses ideológicos, que freqüentemente conduz à criminalização da pobreza (Debarbieux, Blaya, 2002; Debarbieux, 2002). Não cabe negar, contudo, os seus efeitos diretos e indiretos sobre a freqüência, o aproveitamento do tempo letivo, o rendimento escolar e a própria capacidade de o processo educativo transmitir valores e formar cidadãos capazes de conviver e resolver pacificamente as suas divergências (cf. Abramovay, 2002; Coleman, 1998; Bowen, Bowen, 1999; Gronna, ChinChance, 1999). Os objetivos da escolarização, segundo a literatura, são alcançados em situação de ordem e quando existe um clima favorável na instituição (Scheerens, 2000). Inversamente, a paz na escola comprovadamente conduz a resultados positivos. Portanto, além dos efeitos mais tangíveis da violência sobre o patrimônio, que podem ser mais facilmente estimados do ponto de vista quantitativo (Almeida, 1999), as violências acarretam perda de rendimento discente, de confiança, de auto-estima e um desvio da função educacional de formar valores inerentes à convivência e ao respeito à diversidade.

Por isso mesmo, pesquisadores da Unesco (Waiselfisz et al., 1998) procederam, em 1997, a uma profunda investigação quanto à juventude e à violência no Distrito Federal sob o impacto da morte de Galdino'. Os resultados mostraram que as opiniões dos jovens se dividiram entre a imagem de uma suposta violência menor em Brasília, em relação ao restante do país, ou de uma cidade igual às outras e, ainda, de diferenças entre as cidades satélites e a capital. Foi constatada a tribalização dos jovens, reunidos em gangues e galeras. As primeiras, com território demarcado, são grupos que se reúnem para praticar algum tipo de delito e mantêm rivalidades com outras gangues, embora constituam turmas de amigos. Já as últimas são grupos de amigos que saem unidos para se divertir e que muitas vezes exercem as funções de autodefesa e proteção. As escolas, apesar de uma série de aspectos positivos, foram vistas pelos jovens como instituições alienadas das suas experiências. Embora as particulares fossem melhor vistas que as públicas, ficou realçado o seu despreparo para lidar com a cultura da juventude (cf. também Minayo et al., 1999). O aprofundamento quanto às cidades satélites do Distrito Federal (Abramovay et al., 1999)

I. Trata-se do índio pataxó Galdino de Jesus dos Santos que faleceu em decorrência de um grupo de jovens de classes média e alta ter-lhe ateado fogo ao corpo, em 1997, quando dormia num ponto de ônibus em Brasília. 
revelou que, enquanto espaço urbano, o Distrito Federal é percebido pelos jovens com uma clara segmentação socioespacial, na qual classes e atores sociais apresentam acentuadas desigualdades. Eles se sentiam estigmatizados e excluídos, manifestando também imagens estereotipadas da juventude de Brasília.

Em trabalho mais recente, Abramovay e Rua (2002) focalizaram os diversos tipos de violência nas escolas, constatando que o Distrito Federal ocupa uma posição destacada entre as 14 capitais pesquisadas. Como conseqüência do aumento de atos delituosos ou de seu registro, bem como de pequenas e grandes incivilidades tendo como palco a escola e o seu entorno, difundia-se entre os seus atores não só um sentimento de insegurança, mas também de aversão de parcelas significativas de alunos, que não gostavam dos seus colegas e da própria escola. Por sua vez, muitos membros do corpo técnico-pedagógico afirmavam que o que menos apreciavam eram as aulas e a maioria dos alunos. Ainda que os estabelecimentos particulares como um todo se caracterizassem por menor freqüência de violências, segundo as percepções dos pesquisados, no Distrito Federal, a proporção de alunos que declarou não gostar da escola foi superior nas escolas particulares em relação às públicas.

\section{METODOLOGIA}

Esta investigação, de caráter exploratório, coletou os dados por meio de um roteiro comum de questões para discussão e mediante registro de observações em caderno de campo, tendo-se efetuado nos meses de maio e junho de 2003. O noticiário da mídia no período não apresentou nenhum fato altamente destacado sobre violência, especialmente envolvendo jovens. Os grupos se reuniram nos períodos diurno (nove) e noturno (dois), totalizando I I grupos focais, que foram conduzidos pelos mestrandos, todos professores de educação básica ou superior. Cada grupo contou com oito a doze alunos adolescentes de escolas públicas e particulares da unidade federativa, geralmente com equilíbrio da participação por gênero. Os grupos foram assim distribuídos: dois em duas escolas públicas de cidades satélites da periferia (dois na Escola I e dois na Escola 2), um numa escola pública do Plano Piloto (Escola 3), dois numa escola confessional de uma cidade satélite (Escola 4), dois numa escola confessional do Plano Piloto (Escola 5), um numa escola confessional do Plano 
Piloto (Escola 6) e, ainda, um grupo numa escola leiga também do Plano Piloto. Assim, os resultados foram obtidos com base em cinco grupos em escolas da rede pública e seis da rede privada.

A Escola I, de ensino fundamental, fica numa cidade satélite de baixa renda, que tem fama de violenta. A direção, entretanto, introduziu controles de circulação de pessoas e "transferiu" para outro estabelecimento os alunos que tinham problemas disciplinares. Dessa forma, conforme a expressão de um aluno, "os ruins se juntaram aos piores". Participaram discentes da sétima e oitava séries.

A Escola 2, pública, também de ensino fundamental, localiza-se numa cidade também de baixa renda, conhecida pela violência nos noticiários da mídia. A unidade escolar era organizada, limpa e bem equipada, enfrentava problemas de violência, sendo freqüentada por alunos que pertenciam a gangues rivais. A pesquisa chegou a causar preocupações nesses alunos pelos temas debatidos e o último grupo focal esteve, a partir de determinado momento, sob clima tenso. Os participantes dos grupos focais eram do ensino fundamental, na modalidade educação de jovens e adultos, na faixa de 16 a 18 anos de idade.

A Escola 3 é exclusivamente de nível médio, localizada no Plano Piloto e freqüentada por numerosos adolescentes residentes nas cidades satélites e no entorno do Distrito Federal, que a buscam em virtude da fama de êxito na função propedêutica do ensino médio. Os prédios se encontram mal conservados, a direção não parecia muito presente e o controle de acesso era frouxo (segundo o caderno de campo, qualquer pessoa levando uma mochila entrava facilmente, sem identificação). A escola é freqüentada por membros de gangues, como ficou evidenciado posteriormente pelo noticiário policial, que a manteve como foco em várias ocasiões, inclusive em virtude de um crime praticado nas cercanias. Os alunos participantes dos grupos focais eram das turmas de primeira série e em geral residiam no entorno do Distrito Federal.

A Escola 4 é uma tradicional escola confessional, muito bem instalada e com diversas atividades extra-classe, preocupada com a formação de valores. Situa-se numa cidade satélite de renda relativamente alta. $\bigcirc$ valor da sua anuidade, embora mais baixo que o das escolas do Plano Piloto, estabelece certa seleção social. Ainda assim, foram encontrados alunos que residem em cida- 
des satélites de baixa renda. Os grupos focais foram compostos por discentes da oitava série e da primeira do ensino médio.

A Escola 5 é também uma tradicional escola confessional da cidade, de porte médio, que atende a camadas médias ao longo de todos os níveis da educação básica. Seu projeto pedagógico tem em vista desenvolver a autonomia e responsabilidade, com o foco na construção de sujeitos conscientes e felizes. $\bigcirc$ único grupo focal foi integrado por alunos da primeira série do ensino médio, em média com 16 anos de idade.

Por fim, a Escola 6 é outra tradicional escola confessional, com excelentes instalações e também preocupada com a formação de valores. Mantém o ensino médio e tem prestígio pelo seu currículo acadêmico. $O$ controle do acesso e circulação de pessoas nas dependências é rigoroso, com grande ênfase na segurança. Embora sua anuidade não seja a mais elevada do Plano Piloto, o corpo discente tende a ser das camadas sociais média e alta. Existe seleção intelectual para ingresso de alunos externos.

Deve-se considerar que a maioria dos alunos participantes tinha idade superior à da série que cursava. Essa distorção foi marcante nas escolas públicas, embora também fosse significativa nas escolas particulares. Quanto ao status socioeconômico, a divisão entre escola pública e particular revelou, conforme outras pesquisas, uma espécie de apartheid social. Segundo Cavalcante (2002) e Castro (200 I), no Distrito Federal a rede pública apresenta elevado grau de acesso das populações mesmo de renda muito baixa. Dessa forma, a divisão aqui adotada, de escolas públicas e privadas, constitui uma espécie de proxy do status socioeconômico dos discentes e suas famílias, motivo pelo qual os resultados serão apresentados pela dependência administrativa dos estabelecimentos de ensino. Com efeito, os participantes das escolas públicas eram, de modo geral, filhos de pais que exerciam ocupações manuais e os jovens, quando trabalhavam, também exerciam ocupações manuais, muitas vezes no setor informal. A maioria não havia nascido no Distrito Federal, denotando ter para lá migrado com a família em busca de melhores condições de vida. Por sua vez, os participantes das escolas particulares, em sua maioria, haviam nascido no Distrito Federal, eram filhos de pais que exerciam ocupações não manuais, e os poucos que trabalhavam, em muitos casos, faziam-no em empresas dos pais, a título de trabalho não remunerado. 


\section{A ESCOLA COMO ESPELHO DA SOCIEDADE}

Os resultados indicam, conforme a literatura, que a escola deixou de ser um oásis ou uma ilha e, apesar das medidas por ela tomadas, reflete uma sociedade em que a violência é cotidiana e diuturna. Os participantes, tanto dos estabelecimentos oficiais como dos particulares, tinham conhecimento de pessoas que haviam praticado ou haviam sido vítimas de crimes e contravenções. Nos primeiros, o grande problema destacado foi a freqüência de alunos que pertencem a gangues, com os reflexos sob a forma de lutas entre eles levadas para dentro das escolas e da intimidação e ameaças a outros discentes. Em tais estabelecimentos a presença da polícia e das revistas pode ser comum. A escola pública, aberta a todos, tem ampla heterogeneidade e enfrenta obstáculos para administrá-la. Vários participantes destacaram a adoção de medidas eficazes para manter um clima de relativa segurança na escola (não necessariamente um clima de paz), porém foram acordes em dizer que os arredores são inseguros e causam medo.

Nas unidades escolares privadas destacaram-se os controles, porém foi narrada a ocorrência de numerosas brigas e de episódios de violência verbal, "que pode ser pior que a física", segundo uma participante. Num dos estabelecimentos foi assinalado que alunos introduzem disfarçadamente bebida alcoólica, alguns já a tendo consumido pela manhã, antes de ingressarem no colégio. Com isso, aumenta o estímulo à prática das violências. Mais ainda, foram relatadas as aguçadas rixas entre escolas particulares e entre estas e escolas públicas. No caso de escolas oficiais e privadas o pretexto seria as disparidades sociais do alunado, porém isso não acontece com as escolas privadas. Dessa forma, o pertencimento a um grupo é como se fosse necessariamente a afirmação e a oposição a outro grupo, manifestas por meio da disputa. Não se verifica a coexistência pacífica ou a indiferença, mas uma tensão permanente. Basta o uso do uniforme para provocar atitudes que vão dos insultos verbais à violência física, com os adolescentes, especialmente do sexo masculino, sentindo-se impelidos a agir pela luta, em face da sua identidade sexual. Em certos casos não é preciso o uniforme; basta o simples fato de se saber que os adolescentes são do estabelecimento "inimigo". Estar sozinho é, portanto, um perigo, o que obriga a andar em grupo, a depender dele e a conformar-se às suas normas e ética. 
Com isso, a infância dá lugar à sociedade adolescente, no caso continuamente assinalada pela possibilidade ou ocorrência da violência. Esta sociedade tem valores, lideranças, normas, sanções e símbolos próprios que se afirmam ante a sociedade adulta, representada, entre outras instituições, pela escola e pela família (Coleman, 1963; Cândido, 1973). A busca pela identidade na adolescência e juventude não é nova, porém são mais profundos os processos pelos quais se forma e se mantém uma microssociedade relativamente independente, com a sua própria subcultura, que pode ser oposta à(s) dos adultos. Aparentemente, quanto mais intensos os processos dissociativos, maior é o sentido de coesão dentro de cada grupo que se identifica espacialmente, como pelo pertencimento à escola, à turma, à galera e, sobretudo, à gangue.

Indagados sobre os fatores que geram as violências, os sujeitos das escolas públicas indicaram as desigualdades sociais, o dinheiro e o poder, a falta de atividades para jovens, a discriminação e a "ruindade de certas pessoas". A falta de atividades e de equipamentos sociais é conhecida da literatura e tem ensejado, como alternativa, programas de abertura das esolas nos fins de semana, como o Abrindo Espaços, da Unesco. Já a discriminação não se refere apenas às diferenças entre cidades satélites e Plano Piloto, mas existe dentro da própria vizinhança e da escola:

Você fica é com raiva desse lugar, porque o que você vê é (...) pessoas que vê o jeito de você vestir (...). Fala de você, discriminam, se você tem um do lado de sua casa, se você tem mais dinheiro assim, uma colega ganha 1000, a outra ganha 200, a outra já é pobre, até das próprias pessoas vem a discriminação, até de quem não tem nada. (Escola pública, cidade satélite)

As drogas e a bebida foram também apontadas como fatores de violência, amplamente utilizadas tanto pelas gangues quanto pelas galeras, pelo menos numa relação causal indireta. Igualmente a falta de apoio da família e a pressão dos colegas ("muitas vezes participa de atos de violência e de gangues só pra ficar bem com os amigos, mas nem é que gosta de verdade") contribuem para o conformismo da sociedade adolescente. Observou-se também que um simples olhar é suficiente para ser tomado por provocação, gerando o ato de "encarar" a "necessidade" de uma resposta violenta para afirmação do poder e, em certos casos, da territorialidade do grupo (Abramovay et al., 1999; 
Abramovay et al., 2002). De qualquer forma - e esta foi a grande convergência de opiniões de alunos das escolas públicas e particulares -, as violências podem ser gratuitas e tendem a surgir por motivos fúteis.

Com esse denominador comum, os alunos das escolas particulares, socialmente mais privilegiados, também indicaram as drogas e o álcool, as amizades (a necessidade de "entrar na onda") e, ainda, o exibicionismo². Apesar da violência contida pela escola, esta representava para um grupo de informantes (escola confessional, cidade satélite), um lugar em que se encontram com os amigos, isto é, um lugar de socialização. Para os discentes esta era a primeira função da escola, depois vinha o estudo, que até se aceita ou se tolera em virtude do relacionamento social. Para muitos, a rotina escolar "é uma obrigação, é mais que uma obrigação: é chateação" (depoimento de aluno de escola pública, cidade satélite). No entanto, houve várias menções à qualidade do ensino, à competência docente e aos professores "legais" como pontos altos, tanto em escolas públicas como em particulares.

Quanto à família, se alunos de escola pública citaram a falta de apoio como fator de violências, nas escolas particulares várias falas se revestiram de revolta contra a pressão familiar, que os impedia de ir a determinados lugares e estabelecer relacionamento com certas pessoas. Em conflito com essas normas estava a vontade de experimentar as diversas situações e "ter o direito de errar", direito esse que, no contexto dos grupos e situações, pode ter volta muito difícil. Os pais, conhecendo riscos, estabeleciam proibições:

Só que ele [o pai] sabe que acontece isso [uso de drogas], então ele não deixa a gente sair. Pô, sou filha única do meu pai. Ele não vai querer me perder, tá ligado?! Tipo ele me deixa sob pressão, tá ligado? (escola particular, Plano Piloto)

A proibição pura e simples, porém, parece pouco efetiva sem o diálogo e a persuasão, por afetarem, aparentemente, o desejo de alcançar a identidade e a independência:

2. Amplamente difundidas nas festas e shows, bebidas e drogas são muito difíceis de ser recusadas individualmente quando o grupo toma esse caminho. 
O negócio é que a minha mãe tem preconceito. Tipo assim, a irmã dela fuma maconha. Eu não quero isso. Agora, minha mãe vem me proibir! Quanto mais ela disser não, aí que eu vou querer. Entendeu? Porque é uma coisa lógica (...), uma coisa que sai da gente. A gente faz tudo ao contrário. Se minha mãe falar assim, olha, não faz isso, eu vou fazer, entendeu. (...) Agora, se ela chegar assim e disser: não faz isso porque traz essa e essa conseqüência, aí é outra coisa, entendeu? Dá raiva! A gente contradiz os nossos pais justamente porque a gente quer ter a experiência de errar para aprender. (grupo focal, escola particular, Plano Piloto)

\section{COMO AS ESCOLAS LIDAM COM AS VIOLÊNCIAS?}

As escolas públicas pesquisadas tinham escasso controle sobre acesso e circulação de pessoas no seu interior. Em mais de um caso a direção não estava presente no período de aulas e os pesquisadores não conseguiram contatála, tendo marcado a coleta de dados e obtido informações por meio de coordenadores. Com uma exceção, eram pobres de materiais e apresentavam pichações. As sanções escolares, especialmente advertência e suspensão de até três dias em casos graves, pareciam pouco efetivas. No caso da primeira,

...só que o pai, que tem que assinar, não assina, daí não adianta nada. A escola cobra, mas tem a lei distrital que não pode deixar o aluno sem aula mais de cinco dias, daí acaba. A escola não faz nada e nem taí. (grupo focal, escola, pública, cidade satélite)

Sendo graves os problemas, incluindo o porte de armas as mais variadas, e sendo frágil a autoridade escolar, entrava a Polícia Militar, efetuando revistas dos alunos.

No caso das escolas particulares visitadas, a entrada da Polícia seria impensável. Havia pessoal encarregado da segurança, com comunicação interna e controle rigoroso da entrada e dos movimentos das pessoas. No entanto, segundo alunos, não era só o aparato coercitivo que atuava: "Aqui orienta mais que escola pública" (escola particular, cidade satélite). Com efeito, a execução do projeto pedagógico enfatizava a formação de valores e oportunidades além da sala de aula para a convivência e o desenvolvimento de atitudes. No entan- 
to, a escola confessional, muitas vezes escolhida pelas famílias predominante ou exclusivamente pela qualidade acadêmica, recebe um alunado muito heterogêneo, com suas próprias vivências e orientações, sendo árduo alcançar os objetivos formativos inerentes à sua filosofia.

\section{GANGUES E GALERAS}

O gregarismo dos adolescentes corresponde a uma etapa muito importante de socialização para a vida adulta. Daí formarem suas "tribos", em que afirmam as diferenças em relação a outros grupos etários. Ocorre, porém, que os grupos constituídos podem variar, como as já mencionadas galeras e gangues. Os alunos das escolas públicas relataram diversos casos de roubos, facadas, estupros, brigas em festas e assassinatos ocorridos com pessoas conhecidas ou, em certos casos, com eles mesmos. Grande parte dessas ocorrências se deve à ação das gangues, cuja maioria dos membros não trabalha nem estuda. Elas se baseiam em um código de ética de solidariedade interna e agressão a outros grupos mediante supostas provocações, segundo o princípio "mexeu comigo, mexeu com tudo" (escola pública, cidade satélite). Numerosas, as gangues foram estimadas em mais de 100 numa das menores cidades satélites do Distrito Federal. Elas se formam de maneira bastante regular em ambientes freqüentados por jovens, ou seja, na escola, na área de residência, nas academias ou até nos cursos extra-escolares:

Aí a gangue junta um e outro, daí junta uns |5, juntam o dinheiro, compram drogas, depois armas, depois distribuem entre o pessoal lá e coloca o nome e vira uma gangue para matar os outros. Se um tá com raiva e vai, vão todos juntos para pegar os outros. Se eu não 'tiver com a minha galera e eu 'tiver sozinha, eu posso apanhar para servir de lição para os outros". (grupo focal, escola pública, Plano Piloto)

Embora violentos, outros informantes consideram que os "caras de gangue são pessoas normais, mas são intocáveis". Seus objetivos são variados: pichar, bater, drogar-se. Seus líderes ou chefes são geralmente pessoas mais velhas, de 25 anos para cima, e incluem jovens cada vez mais jovens em busca de proteção. Alguns deles podem ser fracos, incapazes de agir fora do grupo. 
Sua extinção ocorre por prisão pela polícia ou morte dos seus membros. Foi também assinalada a participação feminina:

A GAP também é uma gangue - Gatinhas das Artes Proibidas. Aí tinha uma garota aqui em 200 I e a GAP pegou ela lá embaixo. Teve briga e ficou toda machucada. Quase que quebraram a perna dela. (grupo focal, escola pública, cidade satélite)

Uma das dimensões mais importantes, senão a mais importante, do comportamento da gangue, é a defesa da territorialidade. $O$ espaço por ela definido (físico ou social) é defendido inclusive com ataques contra jovens em grupo, mesmo que não provoquem seus componentes:

Tem gangue que não gosta que se anda em grupo. Isso não tem lógica, acho que é pra comandar, pra ser dono do pedaço. Se eu tô andando com meu grupo e vou passando obviamente se tiver uma pessoa na minha frente eu vou olhar e a pessoa pode achar que eu estou com rixa, entendeu, aí já vai achando que tá todo mundo contra ele, entendeu, aí ele grava e vamos supor que, quando eu estiver sozinha na rua, um monte de gente vem e me bate. (grupo focal, escola pública, cidade satélite)

A irracionalidade foi assinalada por um aluno, pois a gangue bate em quem não conhece, provavelmente em defesa do seu território. Daí a necessidade de andar em grupo, em que o número de componentes e a quantidade de garotos, especialmente "sarados", são fatores relevantes de dissuasão de agressões, particularmente em shows.

Embora muitos dos participantes dos grupos focais conhecessem membros de gangues, afirmaram não pertencer a nenhuma delas, preferindo manter-se a distância para evitar problemas. Eles disseram constituir galeras, unidas em torno de interesses como a música, o esporte ou a escola em que estão matriculados. Elas, no entanto, podem brigar, inclusive galeras compostas só de meninas:

São grupos de amigos que conversam e etc., mas podem brigar também, depende da ocasião... (aluna, escola pública, cidade satélite) 
Minha irmã tinha uma galera, mas não arrumavam briga. Tinha uma amiga dela que tava caçando briga com ela e não agüentou mais e juntou todo mundo (...) e todo mundo começou a brigar. (aluna, escola pública, cidade satélite)

Reunida para "curtir", a galera, ainda que grupo socialmente aceito, pode, portanto, brigar mediante provação real ou suposta, o que serve de mecanismo de defesa, uma vez que as gangues podem atacar grupos menores ou indivíduos isolados. Ambos os grupos, porém, podem fazer uso de drogas, inclusive o álcool, sendo este último socialmente aceitável, o que contribui para eclodir as violências.

Os grupos focais das escolas particulares ratificam essas descrições e revelam que as gangues não são inerentes ao baixo status socioeconômico, nem são típicas das áreas de periferia, onde faltam oportunidades de lazer. Elas também estão presentes no Plano Piloto, nas áreas mais socialmente privilegiadas, tendo inclusive a participação de "mauricinhos". Formam-se com base na rivalidade entre quadras e prédios residenciais, sem que haja qualquer diferenciação sócioeconômica significativa entre os seus componentes. A rivalidade parece derivar de uma simples agregação em torno de um espaço. Também foram mencionadas gangues femininas. A formação desses grupos em geral foi atribuído à disponibilidade de renda e ao fato de Brasília ser a capital, onde se concentra o poder e, em conseqüência, a impunidade. A gangue parece, assim, uma forma de agregação adolescente e juvenil, com propósitos anti-sociais.

QUADRO I

CARACTERÍSTICAS DIFERENCIAIS DE GANGUES E GALERAS

\begin{tabular}{|c|c|}
\hline \multicolumn{1}{|c|}{ Galera } & \multicolumn{1}{c|}{ Gangue } \\
\hline$\bullet$ Junta-se para buscar diversão, "curtição", em & $\bullet$ Junta-se basicamente para brigar, mas pode tam- \\
torno de interesses como música e esporte. & bém pichar ou ter outros propósitos violentos. \\
$\bullet$ Pode ter um estilo definido ou não. • Não se & $\bullet$ Constitui grupos numerosos. • Caracteriza-se \\
preocupa com questões territoriais. • Seus mem- & pela organização e defesa de territórios demarca- \\
bros, socialmente aceitos, estudam e/ou traba- & dos. •É estimulada pela rivalidade. • Seus mem- \\
Iham. •Pode haver galeras masculinas, femininas & bros, com dificuldade de aceitação social, muitas \\
ou mistas. & vezes não trabalham nem estudam. • Pode haver \\
& gangues masculinas, femininas ou mistas. \\
\hline
\end{tabular}


A galera também constitui um grupo de proteção, como nas cidades satélites, embora vulnerável, ao ataque das gangues. Do mesmo modo, é um grupo de lazer que, no entanto, pode "brigar". A gangue e a galera, desse modo, são formas de organização adolescente e juvenil que transcendem as linhas de classe social e as áreas da constelação de cidades do Distrito Federal. $\bigcirc$ quadro I sintetiza as declarações dos sujeitos pesquisados, que constituem uma visão de membros declarados de galeras sobre gangues, tanto de escolas públicas como particulares.

\section{COMO É VIVER NO DISTRITO FEDERAL?}

As opiniões dos alunos de escolas públicas se dividiram entre a tranqüilidade existente nas cidades do entorno e o medo da violência. Naquelas cidades todos se conhecem, disseram alguns, de modo que é mais difícil praticar assaltos, inclusive porque a renda é mais baixa. Os criminosos se dirigem, então, a Brasília, onde a prática de seus atos dá maior retorno. Além disso, na capital ocorrem condutas violentas:

O fato de morar aqui em Brasília é o caso de assalto, violência, não pode sair para uma festa. $O$ fato de esbarrar em uma pessoa já é motivo de morte (...). Você se sente inseguro, tem que ficar no seu canto. Não pode olhar para ninguém, para namorada de um. Vai adivinhar se a menina que tu tá olhando tem namorado?! (grupo focal, escola pública, Plano Piloto)

Quanto às cidades satélites, os informantes assinalaram não só a falta de equipamentos e serviços de lazer ("não tem o que fazer"), a deficiência em geral dos serviços públicos e a falta de emprego, mas também a presença da violência, sob a forma de assaltos, estupros, uso de drogas e suas conseqüências. Para os alunos de Brasília, a cidade tende a ser violenta, enquanto para alguns das cidades satélites ela pode ser mais violenta ou, ao contrário, ter mais acidentes de trânsito e menos fatos de violência. No entanto, o Plano Piloto foi considerado mais moderno, mais bonito, com melhor transporte e policiamento que as outras cidades do Distrito Federal.

Para os alunos das escolas particulares, as opiniões também se dividiram. Para alguns "é bom, mas, ao mesmo tempo, é parado" (escola particular, Pla- 
no Piloto). Alguns dos informantes com maior poder aquisitivo são os que reclamam da falta de lazer. Segundo a maior parte das opiniões, Brasília não é uma cidade interiorana, embora não se compare a São Paulo e ao Rio em termos de violência, apesar de algumas discordâncias. Possui muitos equipamentos e serviços, concentrados no Plano Piloto, inclusive shopping centers (não mencionados nos grupos focais das escolas públicas), associando as vantagens de ser uma cidade menor. Porém, se tem de tudo, também tem violência. $\bigcirc$ temor da violência é amplamente difundido. Por isso, é preciso saber onde tem briga e "dá para saber e evitar", ou seja, respeitar a territorialidade de certos grupos.

Todavia, vários participantes mencionaram a frieza e o isolamento social de Brasília. Como há abundância de equipamentos privados de lazer, as pessoas não se encontram:

No Lago Norte a gente não conhece quase ninguém da rua. Tipo, eu só conheço dois vizinhos, mas são muito distantes e um deles eu só sei o nome. O outro eu conheço porque é daqui da escola. É muito estranho não conhecer gente, os vizinhos, mas como todo mundo tem sua piscina, seu campo de futebol etc. acaba que ninguém se vê. (grupo focal, escola particular, Plano Piloto)

\section{OS ESTEREÓTIPOS E O DIÁLOGO DE SURDOS}

Os juízos de valor pré-formulados, sob a forma de representações ou imagens mentais que indivíduos fazem dos membros de outros grupos, baseiam-se em impressões, opiniões, conjeturas ou em conhecimento incompleto e imperfeito. Essas generalizações são os estereótipos, conforme o pioneiro Thales de Azevedo (1966), verdadeiras lentes que distorcem as imagens e dificultam a comunicação entre pessoas e grupos sociais. $\bigcirc$ Distrito Federal, com a sua segmentação em cidades e quadras, é fértil em estereótipos mútuos, com desvantagem para as cidades satélites. Segundo os participantes, a mídia contribui muito para isso, com o noticiário contundente de crimes selecionados, que causam temor a outras populações ("lá todo dia morre gente") e a utilização de apelidos depreciativos, como o de Rocinha para uma cidade satélite. As discriminações sociais se associam, assim, à localização espacial: 
O pessoal do Lago Sul faz a maior diferença com a gente. O patrão da minha mãe um dia disse para ela que quem é do Lago Sul é a comida e quem é de (nome da cidade satélite) é a sobra. Eu acho um preconceito muito sério, ele é igual à gente, ele só tem dinheiro. (aluna, escola pública, cidade satélite)

A discriminação, muito presente, é multidimensional, incluindo a idade e a série que o aluno está cursando. A beleza, o peso, a cor e outros atributos físicos, predominantemente para a menina, são objeto de divisões internas nos próprios grupos sociais das cidades satélites e têm repercussões no contato com grupos privilegiados socialmente:

Para a sociedade, você tem que ser do jeito que a pessoa gosta, não pode ser tão magra, nem tão gorda também, não pode ser tão negra, nem tão branca... então tem que arrumar uma máquina. (escola pública, cidade satélite)

Os estereótipos incidem no próprio relacionamento entre alunos, no mesmo estabelecimento, com discriminação baseada na aparência e no modo de se vestir e calçar:

Tem umas meninas que vêm todas arrumadinhas e vêem a gente de sandalinha e dizem: "Essa aí é pobre". É claro que tem preconceito, porque é do Plano é tudo filhinho de papai, da cidade satélite é tudo marginal (...). Se você andar assim, com menina até do colégio que eu estudava em [nome de cidade satélite de maior renda], o pessoal que morava em outras cidades era pra um lado e o pessoal tipo assim, até as pessoas que moram lá se sentem diferente, de chegar assim, pra uma patricinha, pra uma menina, assim, que tem mais condições. As pessoas (...) têm vergonha de chegar nessa pessoa que anda melhor, entendeu, e conversar, porque a menina que tem uma situação melhor não olha com os mesmos olhos, ela te olha como: "Ah, mora em [nome da cidade satélite], ih! Naquele lugar que morre gente todo dia?" É, aí a gente fica manjada de todo mundo falar. (grupo focal, escolas públicas, cidades satélites)

Nas escolas particulares, por sua vez, os pesquisados também declararam que há muita discriminação, dependendo da roupa e outras características, entre escolas públicas e particulares e entre o Plano Piloto e as cidades satélites: 
O pessoal da satélite não se mistura, eles não gostam de se misturar. Eles começam a achar que nós vamos formar uma gangue e atacar eles. Eles nos chamam de riquinho. Olham para a gente assim, de cima para baixo. (grupo focal, escola particular, Plano Piloto)

Se muitos afirmam a existência de estereótipos e declaram que tamanhas diversidades em tão pouco espaço causam violências, outros consideram uma riqueza a diversidade de Brasília:

Brasília é um lugar onde as pessoas respeitam. Você vai ao [nome de shopping]. Lá dá de tudo: dá gay, lésbicas. Só que é o seguinte. As patricinhas ficam do lado de dentro do shopping, os roqueiros do lado de fora. E eles conversam. Agora se chegar um mauricinho ali naquele bando já tirando onda... (grupo focal, escola particular, Plano Piloto) $)^{3}$

Parte dos informantes relatou sentir na pele o estereótipo quando viajam, chegando a utilizar carros com placas de outras unidades federativas, num caso, em virtude de apedrejamento. A mídia, segundo os participantes, tem um papel relevante na estigmatização, ao noticiar fatos como o assassinato de Galdino e agressões.

Os resultados mostram que uma sociedade consumista valoriza as manifestações externas de posse, levando até à estratificação interna nas escolas de jovens que se vestem desta ou daquela maneira e dos que moram nesta ou naquela cidade satélite. Nesse processo de discriminação, a imagem estereotipada que se projeta na mídia nacional é a de jovens socialmente privilegiados e impunes que praticam a violência apesar de disporem de amplas oportunidades sociais. Nesse cipoal de estereótipos brotam as divisões que, com freqüência, geram comportamentos violentos, como os mencionados, do "mauricinho" que chega no shopping "tirando onda" dos roqueiros, ou de roqueiros que "mexem" com as meninas em outro centro comercial da cidade, em ambos os casos "saindo da deles" e gerando reações fisicamente violentas.

3. "Patricinhas" e "mauricinhos" são denominações pejorativas dadas aos adolescentes e jovens de classes média e alta integrados à sociedade de consumo. 
As pontes entre os grupos parecem precárias, enquanto os limites parecem ser ciosamente defendidos, inclusive à custa da violência física e verbal.

\section{ESCOLAS PÚBLICAS E PARTICULARES}

As percepções dos alunos de ambos os tipos de escolas apresentam pontos de convergência e divergência (Quadro I). Quanto aos primeiros, as violências nas escolas e nas comunidades, de caráter físico e verbal, aparecem nos dois casos, incluindo-se rixas entre escolas particulares e entre estas e escolas públicas. As violências são relativamente freqüentes, causam medo e geralmente ocorrem por motivos fúteis. As galeras e as gangues existem nas áreas mais e menos privilegiadas socialmente, sendo associações ligadas à adolescência e à juventude, independentemente de diferenças. Como resultado da violência, é arriscado andar sozinho ou, mesmo, em pequenos grupos. A polícia não é bem vista pelos diferentes grupos sociais, orientando-se por estereótipos e agindo, em certos casos, com arbitrariedade. A vida no Distrito Federal, seja nas cidades satélites ou no Plano Piloto, é marcada por violências e riscos. Os grupos destacaram que numerosos estereótipos constituem barreira à comunicação. Portanto, as violências e as associações em gangues e galeras são denominadores comuns das diversas condições sociais dos participantes da pesquisa.

As diferenças aparecem sob vários aspectos. Nas periferias pobres as gangues introduzem violências nas escolas e o entorno destas é inseguro. Também faltam atividades de lazer, que se concentram no Plano Piloto. A família, segundo os relatos, faz pressão contra o envolvimento com violências, no caso de alunos de escolas particulares. Essas violências, por seu lado, são atribuídas ora ao exibicionismo e à impunidade, no caso dos alunos socialmente mais privilegiados, ou aos contrastes sociais, no caso dos alunos menos privilegiados.

As escolas pesquisadas reagem diferentemente às violências. As particulares investem em segurança e controles, ao passo que as públicas, segundo as declarações, são frágeis e têm sanções pouco eficazes. Com isso e tendo em vista a gravidade e freqüência das infrações, entra a detestada polícia, aparentemente solicitada pela direção.

Os estereótipos mútuos são obstáculos à comunicação entre grupos sociais, mas também, em virtude da conduta de alguns, se volta contra os jovens privilegiados de Brasília que viajam para outras unidades federativas. 
QUADRO 2

PONTOS DE CONVERGÊNCIA E DIVERGÊNCIA RELATADOS

POR ALUNOS DE ESCOLAS PÚBLICAS E PARTICULARES

\begin{tabular}{|c|c|c|}
\hline Aspectos & Convergências & Divergências \\
\hline Violências nas escolas & $\begin{array}{l}\text { Ocorrência de brigas e } \\
\text { violências verbais } \\
\text { Rixas entre escolas }\end{array}$ & $\begin{array}{l}\text { Gangues introduzem violência nas escolas } \\
\text { Entorno dos estabelecimentos é inseguro } \\
\text { (públicas) }\end{array}$ \\
\hline $\begin{array}{l}\text { Fatores que geram } \\
\text { violências }\end{array}$ & $\begin{array}{l}\text { Motivos fúteis } \\
\text { Territorialidade das gangues } \\
\text { Pressão dos colegas }\end{array}$ & $\begin{array}{l}\text { Falta de lazer (públicas) } \\
\text { Exibicionismo e impunidade (particulares) } \\
\text { Contrastes sociais (públicas) } \\
\text { Pressão contrária da família (particulares) }\end{array}$ \\
\hline $\begin{array}{l}\text { Reações das escolas } \\
\text { às violências }\end{array}$ & & $\begin{array}{l}\text { Investimento em segurança e controles } \\
\text { (particulares) } \\
\text { Fragilidade da segurança (públicas) } \\
\text { Atuação da polícia (públicas) }\end{array}$ \\
\hline Gangues e galeras & $\begin{array}{l}\text { Associações de adolescentes e } \\
\text { jovens de nas diversas áreas do } \\
\text { Distrito Federal, envolvendo } \\
\text { variadas condições sociais } \\
\text { Risco de andar isolado, } \\
\text { necessidade de gregarismo }\end{array}$ & $\begin{array}{l}\text { Origem das gangues no dinheiro e } \\
\text { impunidade (particulares) }\end{array}$ \\
\hline Polícia & $\begin{array}{l}\text { Age segundo estereótipos e } \\
\text { vieses } \\
\text { Pratica arbitrariedades }\end{array}$ & \\
\hline $\begin{array}{l}\text { Vida no Distrito } \\
\text { Federal }\end{array}$ & $\begin{array}{l}\text { Percepção de violências } \\
\text { Estereótipos como barreiras à } \\
\text { comunicação entre adolescen- } \\
\text { tes e jovens }\end{array}$ & $\begin{array}{l}\text { Falta de lazer nas cidades satélites } \\
\text { (públicas) } \\
\text { Discriminação por ser pobre ou não } \\
\text { acompanhar padrões de beleza física } \\
\text { (públicas) } \\
\text { Estereótipos contra jovens de Brasília } \\
\text { (particulares) }\end{array}$ \\
\hline
\end{tabular}

\section{CONCLUSÕES}

Segundo o paradigma sociológico do consenso, a escola é um lugar no qual a sociedade transmite valores e prepara seus membros para a vida adulta. Conforme a sociologia durkheimiana, o papel da escola na educação moral é o de desenvolver nos alunos regularidade e autodomínio. As crianças não nascem 
com tais qualidades, mas a escola desenvolve a disciplina, que representa a moralidade da sociedade e uma preparação para a vida. Para a sociologia parsonsiana, a sala de aula é uma agência de socialização, por meio da qual as personalidades individuais são preparadas para o desempenho de papéis adultos. A tônica é o consenso na transmissão de valores, mas no paradigma do conflito a ênfase se situa na tensão contínua entre as gerações (Gomes, 2005).

Segundo o clássico Waller (1967), as escolas são centros de difusão que levam os padrões culturais dos grupos mais amplos às comunidades locais. Há, portanto, um conflito contínuo entre professores e estudantes, pois os primeiros representam o mundo adulto, enquanto os últimos representam a cultura local e dos adolescentes e crianças, que se desenvolve nos interstícios do mundo adulto. $\bigcirc$ ensino implica aprendizagens para as quais os interesses espontâneos dos estudantes em geral não oferecem suficiente motivação. Como conseqüência, professores e estudantes são grupos em conflito latente ou manifesto, o que mesmo uma pedagogia avançada só pode reduzir, mas não eliminar. As forças antagônicas alcançam um equilíbrio precário por meio da disciplina.

Os resultados da pesquisa indicam que o segundo paradigma tem maior poder explicativo para as violências ocorrentes nas escolas, públicas e particulares. Parecem elas panelas de pressão, em que os diferentes grupos se entrechocam, utilizando as violências físicas e verbais. Nas escolas públicas, em particular, as tensões surgem não só do embate entre professores e alunos e entre alunos, mas também resultam de conflitos exógenos à escola, isto é, as lutas de gangues. A violência da sociedade se introduz nos estabelecimentos, acrescentando ou amplificando os conflitos que nela existem potencial ou manifestamente.

Nesse quadro, a escola se move num ambiente social difícil. Dentro e fora dela se estruturam os grupos associativos de adolescentes, gangues e galeras, que possuem seus próprios valores, normas e sistema de status, constituindo estruturas paralelas. A sociedade dos adolescentes, na sua busca de identidade e afirmação ante a sociedade adulta, adquire o seu eixo próprio, como constatou Coleman (1963), e pode antepor-se à escola, limitando e reinterpretando a sua influência como agente educativo. Para um dos grupos focais, recorde-se, o principal papel da escola era o de ser lugar de encontro dos colegas da mesma idade e, secundariamente, numa concessão, um lugar de estudo. Assim, a Revolução Industrial, ao retirar os adolescentes da força de trabalho e definir socialmente uma idade em que o consumo e a liberdade 
permite que esses adolescentes formem a sua própria comunidade, leva-os, por assim dizer, a se separarem do resto da sociedade e a desenvolverem a sua própria vida social, numa idade que se inicia cada vez mais cedo e termina cada vez mais tarde, com o adiamento do ingresso estável no mercado de trabalho e na condição de adulto. Os dados revelaram o quanto o gregarismo é indispensável, inclusive como meio de adquirir relativa segurança, tornando difícil a vida do jovem sozinho e obrigando-o a integrar uma galera ou gangue, em conformidade com seus próprios valores e normas.

Não é, pois, de admirar que os adolescentes desenvolvam uma contracultura capaz de se opor à escola e de levar os indivíduos a concentrar suas energias não no estudo, mas em outras atividades mais prestigiosas para o seu sistema de status, como o esporte, o culto da beleza física etc. Essa contracultura chega a ser responsabilizada, nos Estados Unidos, pela estabilidade dos resultados de testes de rendimento ao longo do tempo, apesar de múltiplos esforços para que se elevem (Riordan, 2004). Portanto, é um engano a escola dirigir-se a indivíduos, conforme a lição de Coleman. Cabe a ela dirigir-se a grupos, considerando a sua organização e valores para obter resultados intelectuais e para infundir valores, inclusive os de uma cultura de paz. Trata-se, por conseguinte, de uma revisão de objetivos e estratégias, considerando inclusive que a adolescência, definida em países industrializados com estímulos consumistas, se desenvolve, na teia da mundialização, num país marcado por fortes disparidades sociais e diferentes regimes de participação. Tais contrastes entre áreas e grupos mais e menos aquinhoados aumentam nas possibilidades de violência na escola e no seu entorno.

Neste quadro insere-se a educação dos valores, da formação de atitudes e da construção de uma cultura de entendimento e respeito à diversidade como riqueza. Cabe lembrar que cinco dos onze grupos focais reuniram-se em escolas confessionais, com filosofia própria e preocupadas com as dimensões propriamente educativas em seus projetos pedagógicos. Apesar disso, sem que se tenha tentado mensurar a sua freqüência, as violências se revelaram nelas presentes, não obstante os controles adotados. $\bigcirc$ processo educativo não parece, pois, conseguir integralmente os seus objetivos. Tal fato foi analisado por outras pesquisas. Stein (1998) constatou que quase um terço de alunos e de professores de um grupo de escolas católicas de ensino médio do Distrito Federal concordou que as orientações da Igreja não chegam às salas de aula. 
Quase a metade, também de docentes e discentes, concordou que a preocupação com a sobrevivência financeira, as aprovações e o sucesso no vestibular impediam de tratar das orientações confessionais. Por sua vez, Síveres (200 I), pesquisando uma universidade católica, verificou que o seu ideário era bastante teórico e conseguia se manifestar entre os alunos apenas de maneira parcial. Entre eles prevalecia o forte interesse na formação estritamente profissional, desconsiderando uma formação humana mais ampla. Nos dois casos, o "pragmatismo" de professores, alunos e também de pais parece secundarizar os valores inerentes à educação, mesmo quando escolhem uma instituição católica. No entanto, a falta de determinados valores e a adoção de outros, como os resultados desta pesquisa sugerem, leva a descaminhos arriscados aos jovens e à comunidade.

A escola pública, segundo as normas, também se preocupa com valores e os insere em seus projetos pedagógicos. Todavia, como se constatou, também tem dificuldade de estabelecer a convivência e enfrenta problemas muito graves, que se relacionam inclusive com a pobreza e a exclusão social.

Eis assim que a escola, à parte o fato da sua dependência administrativa, se depara com desafios de grande porte. As violências não são localizadas, são transversais e atingem, no foco deste trabalho, adolescentes e jovens das mais variadas condições sociais. Sua organização por idade transcende também o status socioeconômico. Cria-se uma sociedade com valores, status, recompensas e sanções próprios, em relação à qual a escola precisa se posicionar e atuar como agente de socialização. A sociedade adolescente se parece com uma cápsula que, sujeita ao rolo compressor da mídia, firma um limite às influências escolares e familiares. Tudo isso, envolvido num conjunto de estereótipos e divisões sociais mesmo dentro de cada escola e quadra, para os quais a mídia contribui. Certamente é necessário uma pedagogia coerente e habilidosa que reformule as maneiras de agir que têm sido até agora empregadas. Estas não se revelam efetivas no sentido de reverter o uso das violências, que, na sociedade adolescente, parece antecipar as práticas da sociedade adulta do futuro (Coleman, 1963).

Por sua vez, trabalhos mais recentes, da sociologia da experiência escolar (Dubet, Martuccelli, 1996), destacam que cada situação escolar é caracterizada por uma combinação particular de três lógicas de ação: de integração, em que o aluno se define em razão de ser parte da organização escolar, mas sobretudo do mundo da cultura juvenil; de estratégia, na qual o aluno age con- 
forme o que é melhor para seus interesses escolares, e de subjetivação, em que ele é um sujeito em construção, à distância dos outros dois registros de ação e em busca da autenticidade pessoal.

Parece que a recomendação de Coleman para atingir sobretudo os grupos sociais e não só os indivíduos, bem como a ênfase de Dubet e Martucelli, ainda estão por ser levadas às últimas conseqüências. Ao contrário da sociologia clássica da educação, parece que muitas escolas continuam a agir como se as normas pudessem afetar de fora para dentro, as sociedades adolescentes e juvenis, sem reconhecer o seu protagonismo. Essa visão simplista não tem mais lugar em face do conhecimento sobre a complexidade das relações sociais. Nesse sentido, a mediação, ao preparar alunos para exercerem um papel relevante nas disputas entre os colegas, pode valer-se da própria dinâmica dos grupos discentes, com sua ética, valores e normas, para construir uma cultura de paz na escola.

\section{REFERÊNCIAS BIBLIOGRÁFICAS}

ABRAMOVAY, M. Violências nas escolas. Brasília: Unesco; Instituto Ayrton Senna, 2002.

ABRAMOVAY, M.; RUA, M. G. (coords.) Violências nas escolas. Brasília: Unesco; Instituto Ayrton Senna, 2002.

ABRAMOVAY, M. et al. Escola e violência. Brasília: Unesco, UCB, 2002.

Gangues, galeras, chegados e rappers: juventude, violência e cidadania nas cidades da periferia de Brasília. Rio de Janeiro: Garamond, 1999.

ALMEIDA, S. M. G. Vandalismo na escola e a dinâmica curricular. Brasília, 1999. Dissert. (mestr.) Universidade Católica de Brasília.

AZEVEDO, T. Cultura e situação racial no Brasil. Rio: Civilização Brasileira, 1966.

BOWEN, N. K.; BOWEN, G. L. Effects of crime and violence in neighborhoods and schools on the school behavior and performance of adolescents. Journal of Adolescent Research, v. 14, n.3, p.319-342, July 1999.

CÂNDIDO, A. A Estrutura da escola. In: PEREIRA, L.; FORACCHI, M. M. (orgs.) Educação e sociedade: leituras de sociologia da educação. 6. ed. São Paulo: Nacional, 1973. p. I07- 28.

CASTRO, P. E. M. A Utilização do tempo pelo aluno do ensino médio público. Psicologia da Educação, São Paulo, n. 12, p.69-88, $1^{\circ}$ sem. 2001. 
CAVALCANTE, A. F. Ensino público: gratuito, em termos - custos indiretos do ensino médio para os alunos das escolas públicas do Distrito Federal. Em Aberto, Brasília, v. 19, n.75, p.| |3-122, jul. 2002.

COLEMAN, J. S. The Adolescent society. the social life of the teenager and its impact on education. New York: The Free Press of Glencoe, 1963.

Schoolviolence and student achievement in reading and mathematics among eighth graders. Urbana-Champaign, 1998. (Ph. D.) dissert. University of Illinois.

DEBARBIEUX, É. Violência nas escolas: divergências sobre palavras e um desafio político. In: DEBARBIEUX, É.; BLAYA, C. (orgs.) Violência nas escolas e políticas públicas. Brasília: Unesco, 2002. p.59-92.

DEBARBIEUX, É.; BLAYA, C. (orgs.) Violência nas escolas: dez abordagens européias. Brasília: Unesco, 2002.

DUBET, F; MARTUCCELLI, D. À l'école: sociologie de l'experience scolaire. Paris: Du Seuil, 1996.

GOMES, C. A. A Educação em novas perspectivas sociológicas. 4.ed. São Paulo: EPU, 2005.

GRONNA, S. S.; CHIN-CHANCE, S. A. Effects of school safety and school characteristics on grade 8 achievement. a multilevel analysis. In: AERA ANNUAL MEETING, Montreal, 1999. (Paper presented)

MINAYO, M. C. S. et al. Fala galera: juventude, violência e cidadania na Cidade do Rio de Janeiro. Rio de Janeiro: Garamond, 1999.

RIORDAN, C. Equality and achievement. 2.ed. New Jersey: Pearson; Prentice Hall, 2004.

SCHEERENS, J. Improving school effectiveness. Paris: Unesco International Institute for Educational Planning, 2000.

SÍVERES, L. A Dimensão humana no processo educacional. Brasília: Universa, 2001 .

STEIN, G. B. A Educação nos documentos da Igreja Católica Apostólica Romana e como suas orientações chegam às salas de aula, em escolas católicas do Distrito Federal. Brasília, 1998. Dissert. (mestr.) Universidade Católica de Brasília.

WAISELFISZ, J. J. et al. Juventude, violência e cidadania: os jovens de Brasília. São Paulo: Cortez; Brasília: Unesco, 1998.

WALLER, W. The Sociology of teaching. New York: Wiley \& Sons, 1967.

Recebido em: fevereiro 2005

Aprovado para publicação em: novembro 2005 